Kansas State University Libraries

New Prairie Press

\title{
SOIL PROPERTIES AND LANDTYPES--CLASSIFICATION AND IDENTIFICATION WITH DISCRIMINANT ANALYSIS
}

\author{
R. David Hammer \\ John W. Philpot
}

Follow this and additional works at: https://newprairiepress.org/agstatconference

Part of the Agriculture Commons, and the Applied Statistics Commons

\section{(c) (1) $\Theta(9$}

This work is licensed under a Creative Commons Attribution-Noncommercial-No Derivative Works 4.0 License.

\section{Recommended Citation}

Hammer, R. David and Philpot, John W. (1992). "SOIL PROPERTIES AND LANDTYPES--CLASSIFICATION AND IDENTIFICATION WITH DISCRIMINANT ANALYSIS," Conference on Applied Statistics in Agriculture. https://doi.org/10.4148/2475-7772.1409

This is brought to you for free and open access by the Conferences at New Prairie Press. It has been accepted for inclusion in Conference on Applied Statistics in Agriculture by an authorized administrator of New Prairie Press. For more information, please contact cads@k-state.edu. 


\title{
Soil Properties and Landtypes-- Classification and Identification with Discriminant Analysis
}

\author{
R. David Hammer \\ Assistant Professor of Soil Science, University of Missouri, Columbia
}

John W. Philpot

Professor of Statistics, University of Tennessee, Knoxville

\begin{abstract}
Intensive land use is requiring more detailed information about patterns and magnitudes of soil variability than can be acquired through traditional soil survey techniques. Discriminant analysis is a mathematical method of numerical classification which could be used to identify discrete populations of soils in their natural settings. The hypothesis of this study was that discriminant analysis could be used to group soils on landtypes on the Mid-Cumberland Plateau. A large data set (132 observations of 29 soil variables) was collected from three landtypes at two Cumberland Plateau locations. Discriminant analysis was used to classify the soil observations into landtypes. Canonical correlation was used to identify soil properties most responsible for separating soils into groups related to landtypes. Not all of the collected soil properties were important discriminators, so variables with low canonical loading scores were eliminated. A total of 13 soil variables representing three genetic soil horizons was required to correctly classify all 132 observations into correct landtypes. Canonical correlations were 0.979 and 0.970 with 29 variables and 0.968 and 0.941 with 13 variables on canonical variates one and two, respectively. Soil variables from Bt horizons alone did not classify all observations into correct landtypes. Discriminant analysis, in conjunction with canonical correlation, shows promise for identifying key variables for numerically classifying soils into related populations.
\end{abstract}

Key words: canonical canonical correlation, multivariate statistical procedures, canonical loading scores.

\section{Introduction}

\section{The Soil Classification System}

Soil classification In the United States relies upon Soil Taxonomy (Soil Survey Staff, 1975), a hierarchical system with six levels of classification. Differences, however slight, at any level of the system can taxonomically separate otherwise similar soils into mutually exclusive groups.

Soils generally exist as a multivariate continuum across the earth's surface. Only when soils are considered within local areas do discrete, relatively homogeneous populations become apparent (Arkley, 1976). The perspective from which the resource has been viewed has for decades affected man's attempts to separate soil individuals from the continuum (Cline, 1961). Soil Taxonomy allows the observer to arbitrarily select the pedon (a single soil profile) as the unit of observation. Thus an infinite number of individuals is possible within a sampling area of any size (Knox, 1965). This sampling

* Contribution from the Missouri Agricultural Experiment Station. Journal Series Number 11,737 . 
approach, coupled with the hierarchical classification system, can result in the same soil population being sampled and classified differently by different observers. Young (1992) identified 28 taxonomic classes in 120 observations of a single mapping unit.

Some soil scientists recognized that specific soils, represented by certain combinations of soil properties, appear at predictable places in the landscape (Daniels et al., 1971; Knox, 1965; Ruhe, 1956; Simonson, 1959). This pedictability results because water is the driving force for genesis of both landforms and soils. The specific soils are usually found in association with specific land surface features (Daniels and Hammer, 1992). Unfortunately, the scale at which soils are mapped (the most common mapping scale is 1:24:000, or 1 inch $=2.6$ miles) prohibits delineation of smaller units, regardless of their predictability or frequency of occurrence. Additionally, attention is often focused upon locating the preconceived "representative pedon" of a soil series at the expense of quantifying magnitudes and patterns of soil variance.

Increasingly, users of soil surveys are demanding precise mapping units which include quantification of soil variance. Some scientists have focused upon the landform as the observable indicator of relative soil homogeneity (Daniels et al., 1971; Hammer, 1991; Rowe, 1984; Smalley, 1979; Smalley,1991).

A landform is a surficial feature identified by its shape (concave, or convex) and location in the landscape (Ruhe, 1975). Soil scientists and geomorphologists often refer to landforms as geomorphic surfaces and include the depositional environment and internal texture as part of the identifying criteria (Daniels and Hammer, 1992). In this paper, we will use Smalley's (1979) term, "landtype," which is a landform-based ecological mapping unit defined for forest management purposes.

\section{Discriminant Analysis}

Discriminant analysis is a multivariate statistical procedure which can be used to predict group membership from a set of predictors (variables) (Tabachnick and Fidell, 1989). This statistical method appears to have important applications for soil classification, but has received little attention from pedologists.

Norris (1970) described important justifications for the application of multivariate statistical methods to the study of soil science. These methods may reveal previously undefined structure and relationships among the many, often interrelated variables which define soils. Multivariate analysis allows an objective, unbiased examination of the variables, thus ensuring that a priori perceptions do not lead to incomplete or faulty conclusions. Finally, the knowledge of statistical methods required by proper application of multivariate analyses should result in a precise and repeatable conclusion not possible with non-numeric methods (Norris, 1970).

Among the previous applications of discriminant analysis to soil science have been the identification of representative general classes of soil within an extensive geophysical province (Webster and Burrough, 1974) and classification of soil developmental sequences in sand dunes (Berg, 1980). Edmonds and Lentner (1987) reported that discriminant analysis was better able to predict soil response classes than Soil Taxonomy. Lentz and Simonson (1987) used discriminant analysis to classify soils associated with sagebrush communities. Their analysis revealed that soil properties other than those used in Soil Taxonomy were important discriminators among soil classes. We are not aware of any attempts to use a large data set in conjunction with discriminant analysis to examine the relationship of soils to landforms (landtypes).

\section{Hypothesis and Objectives}

Our hypothesis was that the soils on important Mid-Cumberland Plateau landtypes would constitute discrete populations. Further, since soils are multivariate entities (Crowther, 1953; Norris, 1970), discriminant analysis could be used to classify soil according to landtype of origin. The primary objective of this study was to determine if 
classes of soils are associated with landtypes, the most detailed level of a hierarchical forest land classification system developed for the Mid-Cumberland Plateau (Smalley, 1982). If discriminant analysis revealed unique soil classes among landtypes, our second objective was to identify a minimum set of soil properties necessary to separate the soil classes.

\section{Methodology}

\section{The Data}

Three landtypes (study sites) were chosen at each of two locations (Fall Creek Falls State Park and Catoosa Wildlife Management Area) on the basis of Smalley's (1982) landtype criteria and the dominant forest vegetation. Soils were not examined until sites had been selected. Grids were established on each landtype. Each grid had the same interval $(10 \mathrm{~m})$. Each landtype was completely covered by a grid, so grid sizes varied with landtype and location. A total of 132 grid points (observations) was used for all sites. Twenty nine soil chemical and physical properties represented each observation (grid point).

Samples were obtained from the three uppermost genetic soil horizons on upland, north-facing slope, and first order bottom landtypes. The three horizons included surface $(A)$, transition $(A B)$, and argillic $(B t)$. Horizon thicknesses were measured in the field. Soil colors were coded for statistical analyses using the Buntley and Westin (1965) method. Laboratory analyses were from standard procedures (Soil Conservation Service, 1982). The soil variables are listed in Table 1.

\section{Statistical Analyses}

Statistical analyses were conducted with Systat version 5.1 (Wilkinson, 1989) on a Maclntosh SE. Soil variables were eliminated using two procedures. First, any variables not statistically significant $(P>0.100)$ in the first discriminant classification were dropped. Second, after non-significant variables were dropped, a discriminant classification was performed with the remaining variables.

Canonical analysis was also performed, and the standardized canonical loading scores on the two variates were treated like communalities in a principal components analysis. Loading scores were squared and added.

Analysis of the standardized loading scores revealed a bimodal distribution with values ranging from 0.006 to 0.288 . The median was 0.047 . All variables with summed squared canonical loading scores less than 0.047 were dropped. The remaining 13 variables were subjected to another discriminant analysis and to canonical correlation.

\section{Results and Discussion}

Discriminant analysis of all 29 variables resulted in 100\% correct classification of observations into proper landtypes. Canonical correlations were high for both canonical axes $(0.979$ and 0.970 for canonical variates one and two, respectively), and the discrete soil populations were tightly clustered (Figure 1). This analysis indicated a strong relationship between landtypes and soil populations. Discrete classes of soils were related to individual landtypes.

Three of the 29 soil variables (ABthick $(P=0.107)$, Acolor, $(P=0.165)$ and ABexacid $(P=0.176)$ ) did not contribute significantly to the classification. After these variables were removed from the data set, discriminant analysis again resulted in $100 \%$ correct classification of observations into landtypes. Clustering of observations within landtypes was as tight as with 29 variables (Figure 1). 
Canonical loading scores (Table 2) can be interpreted much as loading scores in a principal components analysis (Hammer et al., 1991). The variables with the highest absolute numerical values on each canonical variate are those which contribute the greatest to the spread between classification groups along respective canonical axes. The canonical loading scores can be used to determine which variables are most important in the classification.

Removal from the data set of the 13 variables whose squared and summed canonical loading scores were below the group median did not reduce the accuracy of discriminant classification using the 13 remaining variables. Again, all 132 observations were classified into the correct landtypes. Canonical correlations remained high, and were 0.968 and 0.941 for canonical variates one and two, respectively. However, the canonical loading scores for the remaining individual variables increased and the relationships between soil variables and individual canonical variates became more obvious.

The loading scores indicated which soil variables were separating the populations within landtypes. Table 2 contains the standardized canonical loading scores for all reported analyses. Note, for example, that the canonical loading scores of variable "pHA" changed from 0.390 and 0.215 when it was one of 29 variables in the analysis to 0.527 and 0.00 when it was one of 13 remaining variables. The ambiguity of this variable was reduced, and "pHA" became a more important contributor to canonical variate one in the second analysis after removal of variables with low canonical loading scores.

Also, when the number of soil variables was reduced from 29 to 13 , the $A$ (surface) horizon variables became more strongly aligned with canonical variate one, and subsurface $(A B$ and $B t)$ horizon variables became more strongly aligned with canonical variate 2 . The separations among soil populations on landtypes along canonical variate one is due mostly to $A$ horizon variables and the separation along canonical variate 2 is due mostly to subsurface horizon variables (Figure 2). Note that within the population from the north-facing slope, the spread among observations has increased. Individual observations moved away from the group centroid as the number of descriptor variables was reduced. However, the discrete grouping of observations within landtypes remained strong.

Soil Taxonomy (Soil Survey Staff, 1975) relies strongly upon soil properties in the Bt horizon when classifying soils of the Ultisol soil order. Most of the soils on the north-facing slopes and uplands were Ultisols. Five soil variables from the Bt horizon which most nearly represent the criteria used for taxonomic classification were selected for the final discriminant analysis of the 132 observations (Table 2). Eighteen (18) of the 132 observations were misclassified. This loss of precision accompanying reduction in variables is revealed in Figure 3. The separation between upland and bottom landforms on canonical variate 1 has been lost, and separation between upland and north-facing slope has been lost on canonical variate two. Observations from the northfacing slope have intermingled with upland observations. Nine of the 18 misclassified observations were from the north-facing slope, and seven were classified into the upland landtype. Seven upland observations were misclassified into the slope landtype. The loss of accuracy and precision resulting from eliminating variables from $A$ and $A B$ horizons is quite apparent when Figures 2 and 3 are compared.

\section{Conclusions}

The sampled landtypes are characterized by discrete populations of soils. Evidently, Smalley's (1982) land classification for the Mid-Cumberland Plateau identifies landtypes which represent soil populations. Variables from all three genetic soil horizons are necessary to optimize the numerical soil classification. When only Bt horizon variables were analyzed, a dramatic loss of accuracy and precision resulted. Thus, the reliance of Soil Taxonomy upon a "control section" composed only of Bt horizon 
soil properties decreased the probability of identifying discrete populations of soils across the broader landscape. The possibility of a serendipitous relationship within these data should not be overlooked. However, the high canonical correlations obtained with only 13 soil variables would seem to indicate that the observed relationships are valid.

Lentz and Simonson (1987) also have shown how numerical classification can identify soil properties which are not recognized by Soil Taxonomy, but which are important in a particular ecosystem. Clearly, discriminant analysis and canonical correlation are multivariate statistical procedures offering much promise in discovering previously unobserved relationships of soils to their environments. As Davis (1986) observed in his discussion of the value of multivariate statistical procedures in the geological sciences, "The rigor and objectivity required by a quantitative methodology can compensate in part for insight and experience which otherwise must be gained by many years of work. "

\section{Acknowledgements}

Field and laboratory research were conducted while the senior author was a research associate at the University of Tennessee, Knoxville. The authors thank G.W. Smalley, W.L. Parks, and G.J. Buntley for assistance during the project. The research was a cooperative agreement between the Institute of Agriculture and the U.S.D.A. Forest Service. Partial funding was provided through grant number FS 19-81-34 from the U.S. Forest Service, Southern Forest Exp. Stn., New Orleans, LA.

\section{References}

Arkley, R.J. 1976. Statistical methods in soil classification research. Adv. Agron. 28: $37-70$.

Berg, R.C. 1980. Use of stepwise discriminant analysis to assess soil genesis in a youthful sandy environment. Soil Sci. 129: 353-365.

Buntley, G.J. and F.C. Westin. 1965. A comparative study of developmental color in a chestnut-chernozem-brunizem soil climosequence. Soil Sci. Soc. Am. Proc. 29: $579-582$.

Cline, M.G. 1961. The changing model of soil. Soil Sci. Soc. Am. Proc. 25: 442-446.

Crowther, E.M. 1953. The skeptical soil chemist. J. Soil Sci. 4: 107-122.

Daniels, R.B. , E.E. Gamble, and J.G. Cady. 1971. The relation between geomorphology and soil morphology and genesis. Advan. Agron. 23: 51-88.

Daniels, R.B. and R.D. Hammer. 1992. Soil geomorphology. John Wiley \& Sons, NY.

Davis, J.C. 1986. Statistics and data analysis in geology. 2nd Ed., John Wiley \& Sons., NY.

Edmonds, W.J. and M. Lentner. 1987. Soil series differentiae selected by discriminant analysis based on ranks. Soil Sci. Soc. Am. J. 51: 716-721.

Hammer, R.D. 1991. Landforms, soil and forest growth: Identification and integration with geographic information systems. pp. 121-130 In. D.L. Mengel and D.T. Tews (ed.) Proceedings. Ecological Land Classification: Applications to Identify the Productive Potential of Southern Forests. Jan. 7-Jan. 9, 1991. Charlotte, NC. Southeast Forest Exp. Stat. Gen. Tech. Rep. SE-68.

Hammer, R.D., J.W. Philpot, and J.M. Maatta. 1991. Applying principal component analysis to soil-landscape research--quantifying the subjective. pp. 90-105 In. G.A. Milliken and J.R. Schwenke (ed.) Applied Statistics in Agriculture. Proceedings 1990 Kansas State University Conference on Applied Statistics in Agriculture. April 29-May 1, 1990.

Knox, E.G. 1965. Soil individuals and soil classification. Soil Sci. Soc. Am. Proc. 29: $79-84$. 
Lentz, R.D. and G.H. Simonson. 1987. Correspondence of soil properties and classification units with sagebrush communities in southeastern Oregon: I. Comparisons between mono-taxa soil-vegetation units. Soil Sci. Am. J. 51: 12631271.

Norris, J.M. 1970. Multivariate methods in the study of soil. Soils and Fertiliz. 33: $313-318$.

Rowe, J.S. 1984. Forestland classification: Limitations of the use of vegetation. $p$. 132-147. In. J.G. Bockheim (ed.) Forest land classification: Experiences, problems, perspectives. Proc. Symp., Univ. Wisconsin, Madison. 13-20 Mar. 1984.

Ruhe, R.V. 1956. Geomorphic surfaces and the nature of soils. Soil Sci. 82: 441455 .

Ruhe, R.V. 1975. Geomorphology. Houghton Mifflin, Boston, MA.

Simonson, R.W. 1959. Outline of a generalized theory of soil genesis. Soil Sci. Soc. Am. Proc. 23: 152-156.

Smalley, G.W. 1979. Classification and evaluation of forest sites on the southern Cumberland Plateau. U.S.D.A. Forest Serv. Gen. Tech. Rep. SO-23.

Smalley, G.W. 1982. Classification and evaluation of forest sites on the Mid-Cumberland Plateau. U.S.D.A. Forest Serv. Gen. Tech. Rep. SO-38.

Smalley, G.W. 1991. No more plots; Go with what you know: Developing a forest land classification system for the interior uplands. pp. 48-58. In. D.L. Mengel and D.T. Tews (ed.) Proceedings. Ecological Land Classification: Applications to Identify the Productive Potential of Southern Forests. Jan. 7-Jan. 9, 1991. Charlotte, NC. Southeast Forest Exp. Stat. Gen. Tech. Rep. SE-68.

Soil Conservation Service. 1982. Procedures for collecting soil samples and methods of analyses for soil survey. Soil Survey Invest. Rep. No. 1. U.S.D.A. Soil Cons. Serv., Washington, D.C.

Soil Survey Staff. 1975. Soil taxonomy: A basic system of soil classification form making and interpreting soil surveys. U.S.D.A. Soil Cons. Serv., Agric. Handbook 436, U.S. Govt. Print. Off., Washington, D.C.

Tabachnick, B.G. and L.S. Fidell. 1989. Using multivariate statistics. 2nd Ed. Harper Collins, NY.

Webster, R. and P.A. Burrough. 1974. Multiple discriminant analysis in soil survey. Jour. Soil Sci. 25: 120-134.

Wilkinson, L. 1989. SYSTAT, The system for statistics. Systat, Inc., Evanston, IL.

Young, F.J. 1992. Spatial variability within soil survey map units. M.S. Thesis, Univ. of Missouri-Columbia. 
Table 1. Soil variables used in initial discriminant analysis of soil properties from three Mid-Cumberland Plateau Landtypes.

\begin{tabular}{|c|c|}
\hline Variable Name & Variable Description \\
\hline Ormat & Organic matter content-A horizon only \\
\hline K & Potassium (meq/100g)-A horizon \\
\hline $\mathrm{Ca}$ & Calcium-A horizon \\
\hline $\mathrm{Mg}$ & Magnesium-A horizon \\
\hline $\mathrm{CaAB}$ & Calcium-AB horizon \\
\hline $\mathrm{MgAB}$ & Magnesium-AB horizon \\
\hline $\mathrm{KAB}$ & Potassium- $A B$ horizon \\
\hline $\mathrm{CaBt}$ & Calcium-Bt horizon \\
\hline $\mathrm{MgBt}$ & Magnesium-Bt horizon \\
\hline KBt & Potassium-Bt horizon \\
\hline Athick & A horizon thickness \\
\hline ABthick & $A B$ horizon thickness \\
\hline Btthick & Bt horizon thickness \\
\hline Acolor & A horizon color \\
\hline ABcolor & $\mathrm{AB}$ horizon color \\
\hline Btcolor & Bt horizon color \\
\hline Aexacid & Extractable acidity-A horizon \\
\hline ABexacid & Extractable acididty-AB horizon \\
\hline Btexacid & Extractable acidity-Bt horizon \\
\hline Afine & Fine silt + clay fraction-A horizon \\
\hline Btfine & Fine silt + clay fraction-Bt horizon \\
\hline Acos & Coarse silt + very fine sand-A horizon \\
\hline Btcos & Coarse silt + very find sand-Bt horizon \\
\hline $\mathrm{pHA}$ & $\mathrm{pH}$ in water-A horizon \\
\hline spHA & $\mathrm{pH}$ in $0.01 \mathrm{M} \mathrm{CaCl}_{2}-\mathrm{A}$ horizon \\
\hline $\mathrm{pHAB}$ & $\mathrm{pH}$ in water- $\mathrm{AB}$ horizon \\
\hline spHAB & $\mathrm{pH}$ in $0.01 \mathrm{M} \mathrm{CaCl}_{2}-\mathrm{AB}$ horizon \\
\hline $\mathrm{pHBt}$ & $\mathrm{pH}$ in water-Bt horizon \\
\hline $\mathrm{spHBt}$ & $\mathrm{pH}$ in $0.01 \mathrm{M} \mathrm{CaCl}_{2}-\mathrm{Bt}$ horizon \\
\hline
\end{tabular}




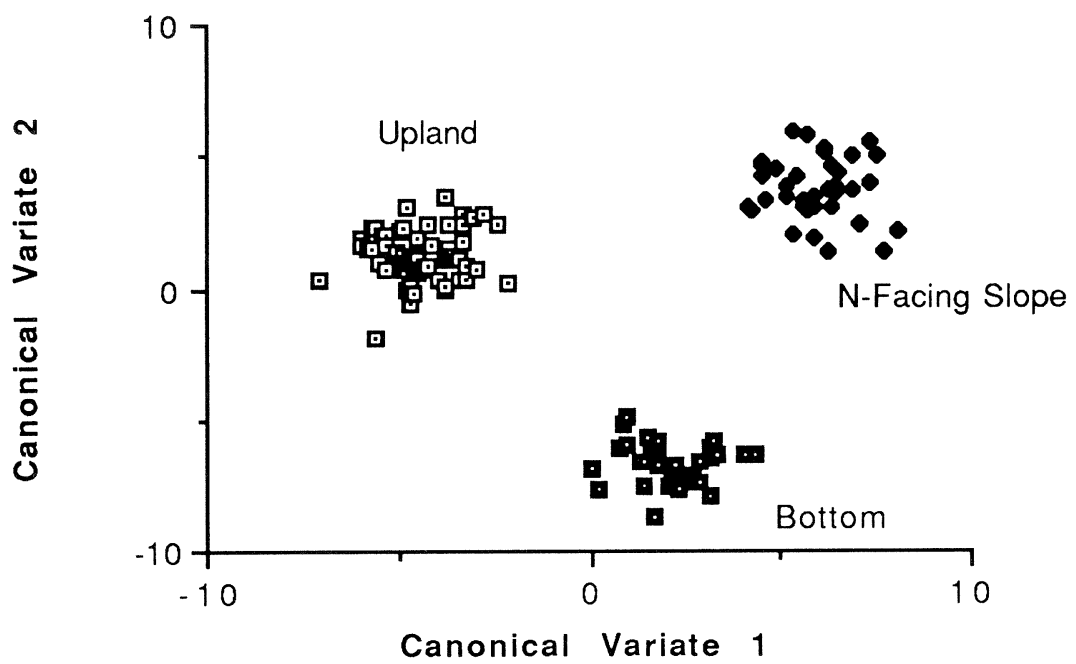

Figure 1. Canonical plots of 29 soil variables from 132 sampling points on three Mid-Cumberland Plateau landtypes.

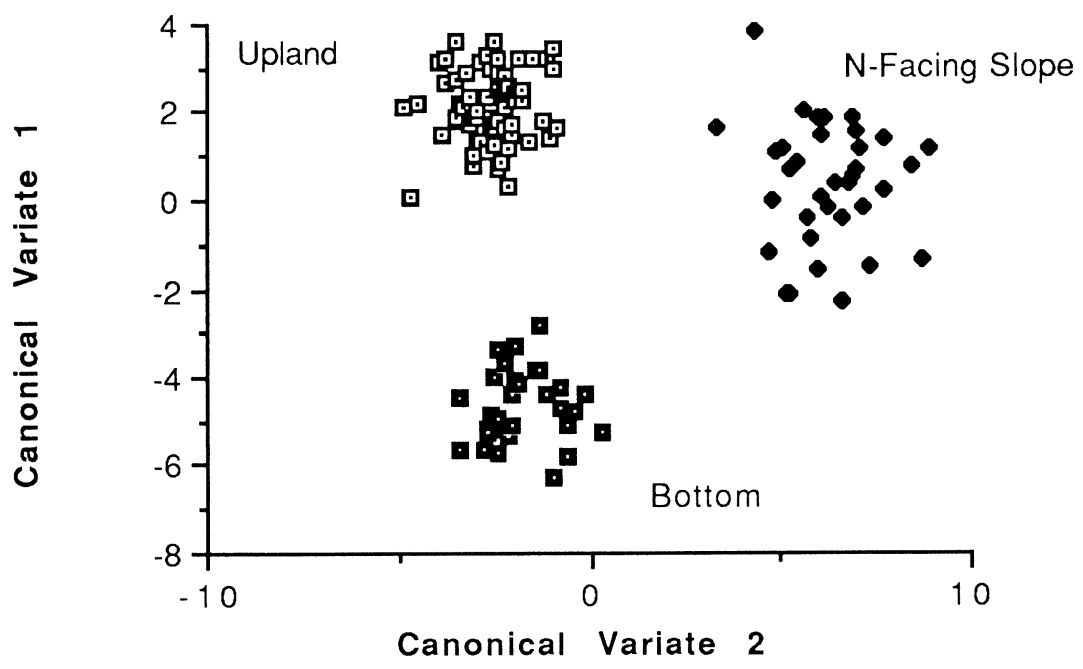

Figure 2. Canonical plots of 13 soil properties from each of132 sampling points on three Mid-Cumberland Plateau landtypes. 
Table 2. Standardized canonical loadings of variables used in discriminate analyses of three combinations soil variables on the MidCumberland Plateau. Dashed lines (--) indicate the variable was not included in that data set.

29 VARIABLES

Variable CanVar1 CanVar2 CanVar1 CanVar2 CanVar1 CanVar2

Ormat

$\mathrm{K}$

$\mathrm{Ca}$

$\mathrm{Mg}$

$\mathrm{CaAB}$

$M g A B$

$\mathrm{KAB}$

$\mathrm{CaBt}$

$\mathrm{MgBt}$

$\mathrm{KBt}$

Athick

ABthick

Btthick

Acolor

ABcolor

Btcolor

Aexacid

ABexacid

Btexacid

Afine

Btfine

Acos

Btcos

$\mathrm{pHA}$

spHA

PHAB

spHAB

$\mathrm{pHBt}$

$\mathrm{spHBt}$
0.073

0.305

0.312

0.264

0.141

0.146

0.123

0.177

0.165

0.203

0.272

0.022

0.240

$-0.011$

$-0.120$

$-0.040$

$-0.065$

0.018

0.117

0.090

0.081

0.058

0.015

0.390

0.442

0.106

0.076

$-0.012$

$-0.074$
13 VARIABLES

$$
0.024
$$

0.138

0.1470

0.050

0.103

0.171

0.160

0.117

0.169

0.150

0.191

0.039

$-0.349$

$-0.040$

0.209

0.258

$-0.152$

0.036

$-0.120$

0.017

0.103

0.094

0.088

0.215

0.300

0.193

0.051

0.080

0.079
0.399

0.411

0.315

0.237

- -

0.256

0.291

0.385

- -

0.116

- -

$-0.043$

0.067

-.

-

-

- -

$-$

-

-

0.527

0.622

0.202

$-0.032$

$-0.039$

$-0.124$

-

0.117

- -

0.102

0.050

0.053

$--$

$-0.627$

- .

0.358

0.366

$-$

$-\cdot$

$-$

$-$

$-$

-

$-0.00$

0.174

0.176

- -

- -
Bt HORIZON VARIABLES

\begin{tabular}{ll}
- & - \\
- & - \\
- & - \\
- & - \\
- & - \\
- & - \\
- & - \\
- & - \\
- & - \\
- & - \\
- & - \\
- & - \\
- & - \\
- & - \\
- & - \\
0.714 & -0.131 \\
- & -- \\
- & - \\
-0.356 & 0.590 \\
- & - \\
0.262 & 0.474 \\
- & - \\
0.236 & 0.112 \\
- & -- \\
- & -- \\
- & -- \\
- & - \\
0.221 & -0.036 \\
- & -- \\
\hline
\end{tabular}




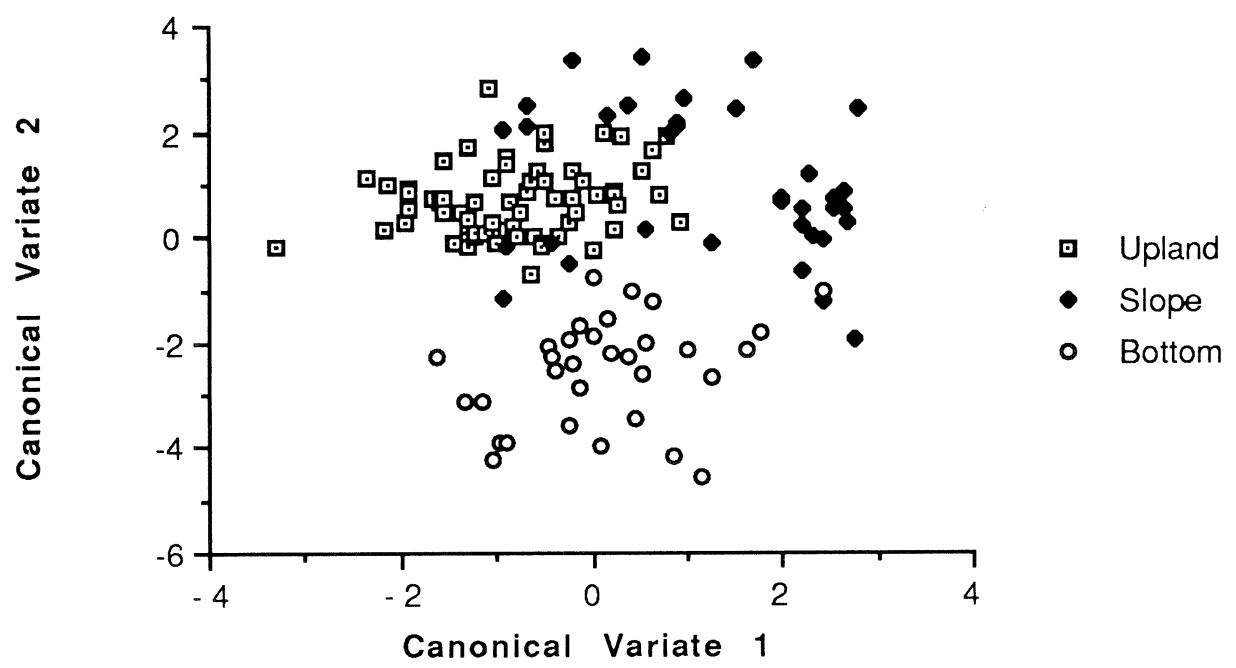

Figure 3. Canonical plots of $5 \mathrm{Bt}$ horizon soil variables from 132 sampling points on three Mid-Cumberland Plateau landtypes. 